\title{
Workplace violence towards nurses: an act of remorse upon feminity
}

Saleema Shoukat Ali Jassani

Nursing intern, Aga Khan University School of Nursing and Midwifery

\section{Introduction}

An intimidating work environment, in which insulting or obnoxious comments, persistent criticism or even physical abuse and threats triumph, is a reality for many employees in both public and private organizations. One novice RN was dealing with a patient in private ward of tertiary care hospital with a 35 year old male patient encountered with physical abuse when the patient touched her one of the private body part while performing IV cannulation. She also experienced unpleasant remarks and dirty gestures of patient as well as his relatives. As the incident took place she immediately stopped doing cannulation and started leaving room but was stopped by the relative and she has to tolerate aggression that she is incompetent which leads her to post traumatic stress syndrome. (Somani \& khowaja, 2012). Violence towards nurses has been seen a major issue in both developing and developed countries and is increasing progressively in society and workplace. The incidence of work place violence is impracticable to find out mostly because of nonreporting behavior of nurses. According to Koch and Hudson (2000) The UK Health and Safety Authority reported that nurses were five times more likely to be attacked than other workers. "Over half of the nurses (52\%) experienced some form of workplace aggression. Thirty-six percent experienced violence mostly from patients or their visitors/relatives and $32 \%$ experienced bullying mostly from colleagues or from their managers/supervisors" (Farrell \& shafiei, 2012). The above mentioned incidences clearly depict the picture of increasing violence at workplace setting which is defined as "workplace violence is, physical assault, threatening behavior or verbal abuse, and racial and sexual harassment occurring in a work setting" (Stanton, 2007). In essence there are two types of violence frequently seen in the health care settings. Physical violence, which is the use of physical force to harm another person that leads to physical or sexual harm which include pushing, kicking, spitting or rape etc. which is more recognized and the other is psychological violence that is intentional use of power against another person that results in harm to mental, social and spiritual development it may include verbal violence, bullying and sexual violence.

There are a number of sources from where violence at workplace arise the roots are deeper and the causes are diverse. Among which lack of respect towards the nursing profession in Pakistani society is on top. Nursing had always been a female dominated profession due to which our society always fails to recognize and sexualize the profession which is the major cause of violence towards nurses and womanhood. Somani and khowaja (2012) discovered that in recent year's media has been displaying nurses in a very negative roles in front of public as resource of sex and subordinates of doctors through different advertisements and serials. On the contrary the cultural beliefs of our society that woman's are substandard group due to this female nurses are thought to be fragile, useless and oppressed and are prone to violence. On the other hand socio-economic factors including homelessness, anxiety, financial burdens and domestic disputes takes one towards more exploitation. In addition inadequate security measures and policies in preventing violence incidents also play a key role in increasing violence towards nurses.

Such episodes of violence may develop radical effects on the health of nurses which may promote disappointing workplace performance and organizations name as well as psychological trauma and Post-Traumatic Stress Disorder in employee victims. As stated by koirhola and niskanen (2012) nurses start losing their self-possession, their sense of worth and faith in their capabilities and may feel powerless, laughable, vulnerable and actually ill. Nurses started blaming themselves as a cause of this incident. Further studies shows that a victim who goes through mental disturbances due to violence and post-traumatic stress disorder can take four to five years to recuperate and a number of not at all do. This unrecovered from stress leads to absenteeism and increased sick leave. Eventually they resign form jobs and organization loses a competent and skilled staff. This increasing violence portray a bad reputation of organization in society as well as it greatly impacts on the image of nurses. The most obvious victim is the person or people whom the violence is directed toward. These individuals are often the ones whose names appear in the paper or media. Unfortunately, because of the media attention, the perpetrator's name often lives on much longer than the victim's and this tear down their image and social life. 
Violence towards nurses is a highlighting issue and has turn out to be a main concern for nurses working in health care settings. Organizations/hospitals must reform zero tolerance policy in order to handle violent incidences. This policy should be circulated in staff, clients, family members, and visitors. Organizations must think upon to bring a change in recruitment, workload, work mores and safe environment. High priority should be given to organizational intervention in preventing workplace violence. Accurate data should be collected and investigation should be conducted in order to minimize exploitation against nursing staff. An antiworkplace violence committee is supposed to develop which must include nurses, for planning strategies and policies for reducing and exposing violent behaviors. Training programs should be conducted for all staffs of the organization consecutively to make them learn the strategies for preventing and dealing with workplace violence. Moreover, they should be told the proper channel to report any violence occurring to them and confidentiality should be maintained. Institutions should optimize safety measures such as monitoring systems, High alert security in night and emergency signaling and alarm system should be set up for the immediate action towards incident. It is the prime responsibility of every individual to not only respect others but to value the rights of others and not to differentiate on the basis of disability, race, cast, color, gender, sexual orientation, or profession. As stated by mcphaul and Lipscomb (2004) government should develop policies and plans at the workplace to combat violence and launch awareness campaigns moreover government should make the reduction of workplace violence in the health sector an essential part of policies and plans. Nurses should also collaborate with the government and hospital and advocate for other nurses. Furthermore, nurses should immediately report any kind of violence happens to them so that instantaneous action could be taken.

\section{Conclusion}

In conclusion, workplace violence is a multifaceted issue in today's health care setting. It is highly essential to promote safe working environment to all health care workers and any workplace violence should be reported and addressed on an immediate basis to prevent its complications.

\section{References}

- Farrell, G. A., \& Shafiei, T. (2012). Workplace aggression, including bullying in nursing and midwifery: A descriptive survey (the SWAB study). International journal of nursing studies, 49(11), 1423.

- Koch, T., \& Hudson, S. (2000). Preventing workplace violence: toward a best practice model for work in the community. Journal of Occupational Health and Safety, 16(575).

- Korhola, T. L., \& Niskanen, S. (2012, September). WORKPLACE VIOLENCE AGAINST nursing personnel. Ammattikorkeakoulut. Retrieved from http://publications.theseus.fi/bitstream/handle/1 0024/48872/Luoto-

Korhola_Tuuli_Niskanen_Susanna.pdf.pdf?sequen ce=1

- Mcphaul, K. M., \& Lipscomb, J. A. (2004). Workplace Violence in Health Care: Recognized but not regulated. The online journal of issues in nursing, 9(3).

- Somani, R. K., \& khowaja, K. (2012, 08 01). Workplace violence towards nurses: A reality from

- The Pakistani context. Retrieved from http://www.sciedu.ca/journal/index.php/jnep/arti cle/view/582

- Stanton J 2007 Workplace violence. Risk Management June 76-77 